\title{
CIRCUITO BQUEER: TEMPO E IMAGEM NEGRA LGBTQI+ NA AMAZÔNIA PARAENSE'
}

BQUEER CIRCUIT: TIME AND LGBTQI+ AFRICAN AMERICAN

IMAGE IN PARÁ AMAZON

\section{John Fletcher ICA-UFPA}

\begin{abstract}
Resumo
O presente artigo apresenta uma leitura de aspectos memoriais, visuais e conceituais em torno das experiências artísticas de Rafael Bqueer na cidade de Belém durante o ano de 2019. Nesse sentido, propõe identificar, nestas produções, facetas ligadas às temporalidades das imagens, à remontagem de imaginários locais e amazônicos e ao artivismo negro e LGBTQI+. Como base teórica, o diálogo se dá com Georges Didi-Huberman, Walter Benjamin, Ernani Chaves, Djamilla Ribeiro e Achille Mbembe, articulados em uma perspectiva dialógica com relatos $\mathrm{dx}$ artista. As proposições artísticas de Bqueer aqui são tomadas como disparadoras de chaves sígnicas para se acessar determinados dilemas e enfrentamentos de uma produção visual amazônica de alta voltagem política.
\end{abstract}

\section{Palavras-chave:}

Rafael Bqueer; Imagem; Amazônia.

\section{CONSIDERAÇÕES INICIAIS}

Durante o ano de 2019, Rafael Bqueer estabeleceu alguns dos debates artísticos de destaque para a cidade de Belém, bem como para o panorama das artes visuais brasileiras. Inserido em uma série de investigações também legíveis a partir da teoria do ponto de vista ${ }^{2}$, artista e sua rede de memórias, agenciamentos e imagens reiteraram forte crítica à continuidade da experiência colonial, deflagradora de violências e desigualdades étnico-sociais.

As individuais de Rafael Bqueer realizadas neste contexto - POC!!! Perfeita aos Olhos de Cristo e Tupiniqueer -, mais sua participação no Arte Pará 2019orbitam, portanto, em um raio de experiências

\section{Abstract}

This article presents a reading of memorial, visual and conceptual aspects of Rafael Bqueer's artistic experiences in the city of Belém during 2019. In this sense, it proposes to identify, in these productions, facets linked to the temporalities of images, to the reassembly of local and Amazonian imaginary and to black and LGBTQI + artivism. As a theoretical basis, the dialogue takes place with Georges Didi-Huberman, Walter Benjamin, Ernani Chaves, Djamilla Ribeiro and Achille Mbembe, articulated on a dialogical perspective with reports provided by the artist. Bqueer's artistic propositions here are taken as triggers of sign keys to access certain dilemmas and confrontations of a political highvoltage Amazonian visual production.

Keywords:

Rafael Bqueer; Image; Amazon.

interrelacionadas, oportunas para se compreender circuitos visuais amazônicos politicamente engajados para a sensibilização e a transformação social. Nesse sentido, com o intuito de contribuir com uma leitura de marcadores memoriais, visuais e conceituais deste Circuito Bqueer, o presente texto propõe também identificar, nestas produções, facetas ligadas às temporalidades das imagens, à remontagem de imaginários locais e amazônicos e ao artivismo negro e LGBTQI+.

O ano de 2019 já era testemunha de uma Necropolítica ${ }^{3}$ em curso no Brasil, isso antes dos novos capítulos disparados pelo Governo em exercício durante as condições de precariedade 


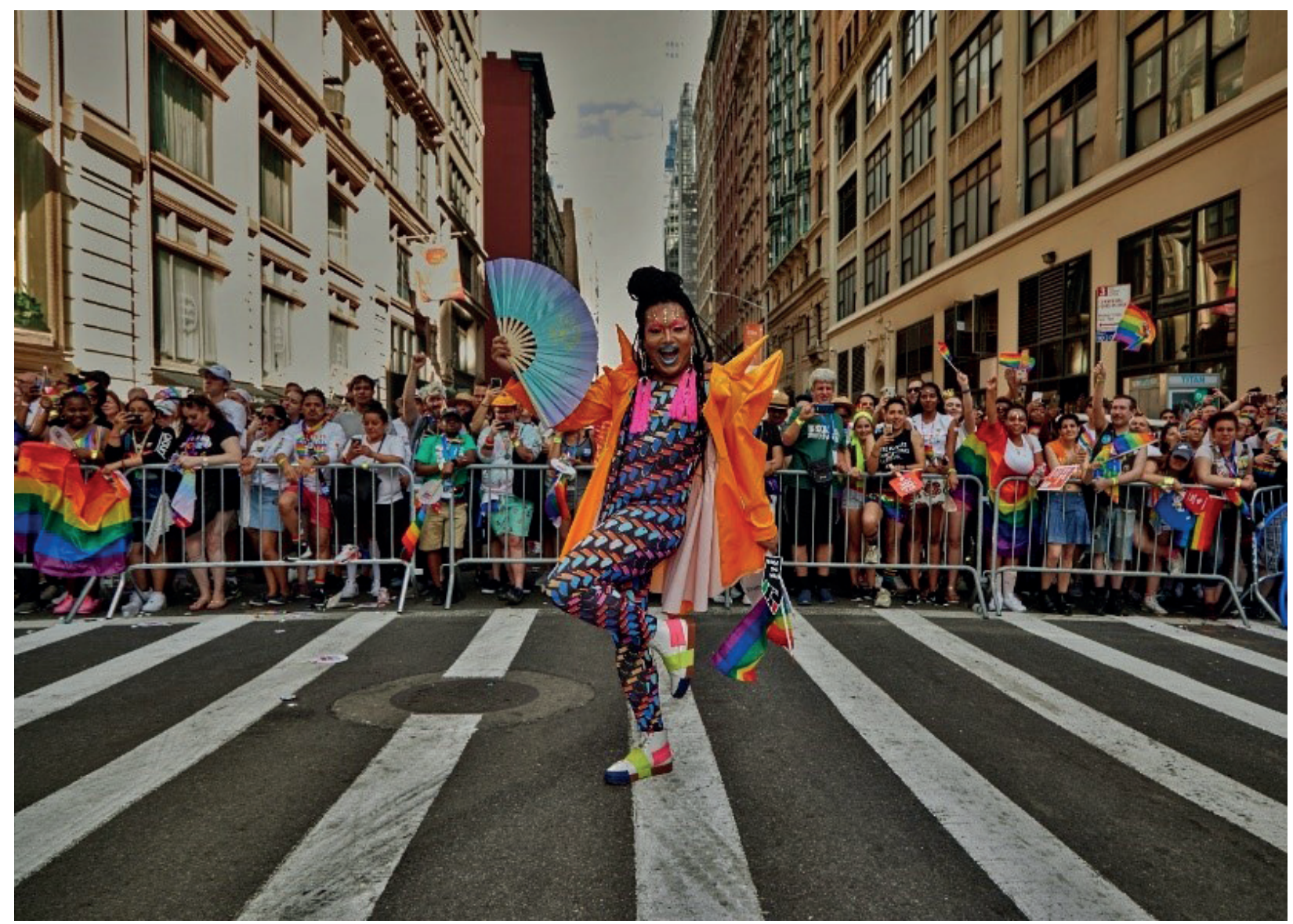

Figura 1 - Rafael Bqueer na Pride de aniversário de 50 anos de Stonewall.

Fotografia: Alex Korolkovas.

afloradas pela Pandemia do Covid-19. 2019, por conseguinte, ficaria marcado como novo estopim cronológico para se dar continuidade a um pensamento plural de resistência e de crítica a modelos de exclusão, de conservadorismo moral e de hierarquização étnico social.

Uma vez que as imagens podem assumir posições, situam-se no tempo, destacamos, a partir do instante que imagens são pensadas em termos de posições, uma dupla faceta, a de afronta e a de aliança com tudo aquilo de que nos afastamos. Ao observar que "tomar posição é desejar, é exigir algo, é situar-se no presente e visar um futuro" (DIDI-HUBERMAN, 2017, p. 15), tomamos estas proposições artísticas de Bqueer como disparadoras de chaves sígnicas para se acessar determinados dilemas e enfrentamentos de uma produção visual amazônica de alta voltagem política.

\section{TEMPOS BQUEER}

Rafael Bqueer tem formação pela Faculdade de Artes Visuais, Universidade Federal do Pará (FAV/
UFPA), e sua produção assume posição no debate visual e político a favor das agendas representativas negras e LGBTQI+ a partir da segunda década do século XXI. Logo no primeiro semestre de 2019, desenvolveu trabalho artístico na $A n n e x B$, espaço de residência artística para brasileiros em Nova York, fruto de bolsa de pesquisa amparada pela própria AnnexB em parceria com a Escola de Artes Visuais do Parque Lage (RJ).

Foi neste primeiro semestre, vale acrescentar, que ocorreu o aniversário de 50 anos da Rebelião de Stonewall, data marco para a luta da comunidade LGBTQI+ por direitos civis nos EUA. A rebelião, cuja linha de frente foi composta pela comunidade negra e trans americana, deu início ao enfrentamento contra o autoritarismo e perseguições da polícia de Nova York. Nesse sentido, Rafael Bqueer, ciente do momento único de sua residência e para uma simbologia da luta para o Brasil, desfilou na Pride de aniversário (Figura 01), em companhia do fotógrafo de moda Alex Korolkovas (paulista residente nos EUA) e do grupo da House of Yes em mais de 03 

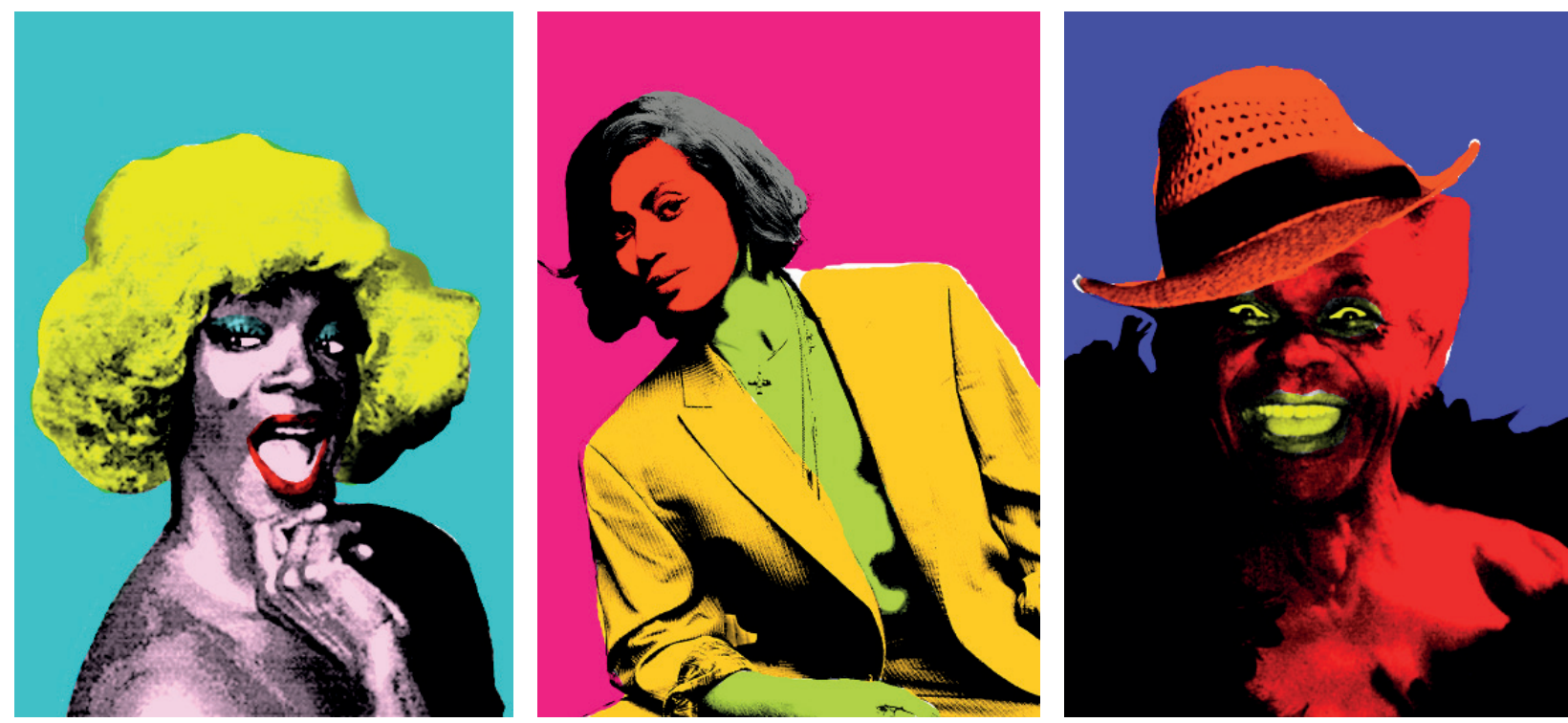

Figuras 2, 3 e 4 - Imagens de Jorge Lafond, Leona Vingativa e Madame Satã, respectivamente, componentes da série UóHol, de Rafael Bqueer. Estas imagens foram integrantes da individual POC!!! Perfeita aos Olhos de Cristo.

Fonte: arquivos $\mathrm{dx}$ artista.

horas de performances, fotografias e vídeos. Em seu percurso, atravessou a Fifth Avenue e terminou em Greenwich Village, passando pelo Stonewall Inn, que foi o local da Rebelião de Stonewall, em 1969 (FLETCHER, 2019).

Além do desenvolvimento de projetos conceituais e performativos em Nova York, a exemplo do desfile na Pride, destacamos que as experiências de Bqueer apresentadas em Belém e aqui neste texto organizadas também tiveram ligação direta com sua residência. Conforme declarado ${ }^{4}$ :

\begin{abstract}
As exposições POC!!!, Tupiniqueer e minha participação no Arte Pará - Malhas Afetivas marcam meu retorno a Belém. Em pleno mês que se comemora a maior procissão católica do Brasil, o Círio de Nazaré. Galerias e instituições da cidade foram invadidas por diversas obras produzidas por mim desde 2014. Uma retrospectiva de imagens profanas e iconoclastas, que desafiam o sagrado e os clichês regionalistas. $O$ corpo e a presença como arte política, como reinvenção, como afirmação de um momento de pensar arte contemporânea a partir de uma perspectiva Decolonial (Rafael Bqueer, Comunicação Pessoal).
\end{abstract}

POC!!! Perfeita aos Olhos de Cristo ${ }^{5}$, apresentada na Kamara Kó com minha curadoria e curadoria assistente de Camila Freire (PPGARTES/ UFPA), teve sua abertura no domingo de 06 de outubro de 2019, dentro da programação do Projeto Circular Campina-Cidade Velha. As obras desta individual, realizadas em uma colaboração de Bqueer com Matheus Aguiar, artista paraense, residente em Belém e performer drag, somaram um total de 07 imagens $^{6}$ (Figuras 02, 03 e 04), complementadas com a apresentação da performance Montação, na qual artista compartilhou o passo a passo de seu processo de auto maquiagem para a plateia de visitantes no vernissage.

A noção de Anacronismo ganha ressonância nesta exposição em foco, já que ilustra um debate contrário a uma perspectiva ainda estrutural e estanque de se compreender imagens e atos criativos. A tônica de Bqueer, a qual se delineou também voltada para questionar uma concepção absoluta de tempo por sua interlocução com a memória, "uma extraordinária montagem de tempos heterogêneos" (DIDI-HUBERMAN, 2019, p. 23), pode então ser tomada como operação capaz de revelar os diferenciais cronológicos operando em cada ato criativo e em cada imagem, legíveis pela interlocução com sua vida pessoal e pelas próprias fontes originárias, respectivamente.

A imagem de Madame Satã (Figura 04), por exemplo, é bem ilustrativa para esta significação, pois, além de agregar, implicitamente, a infância da personagem título marcada pela escravidão em uma fazenda na cidade de Glória de Goitá, interior de Pernambuco, com posterior simbologia de luta 


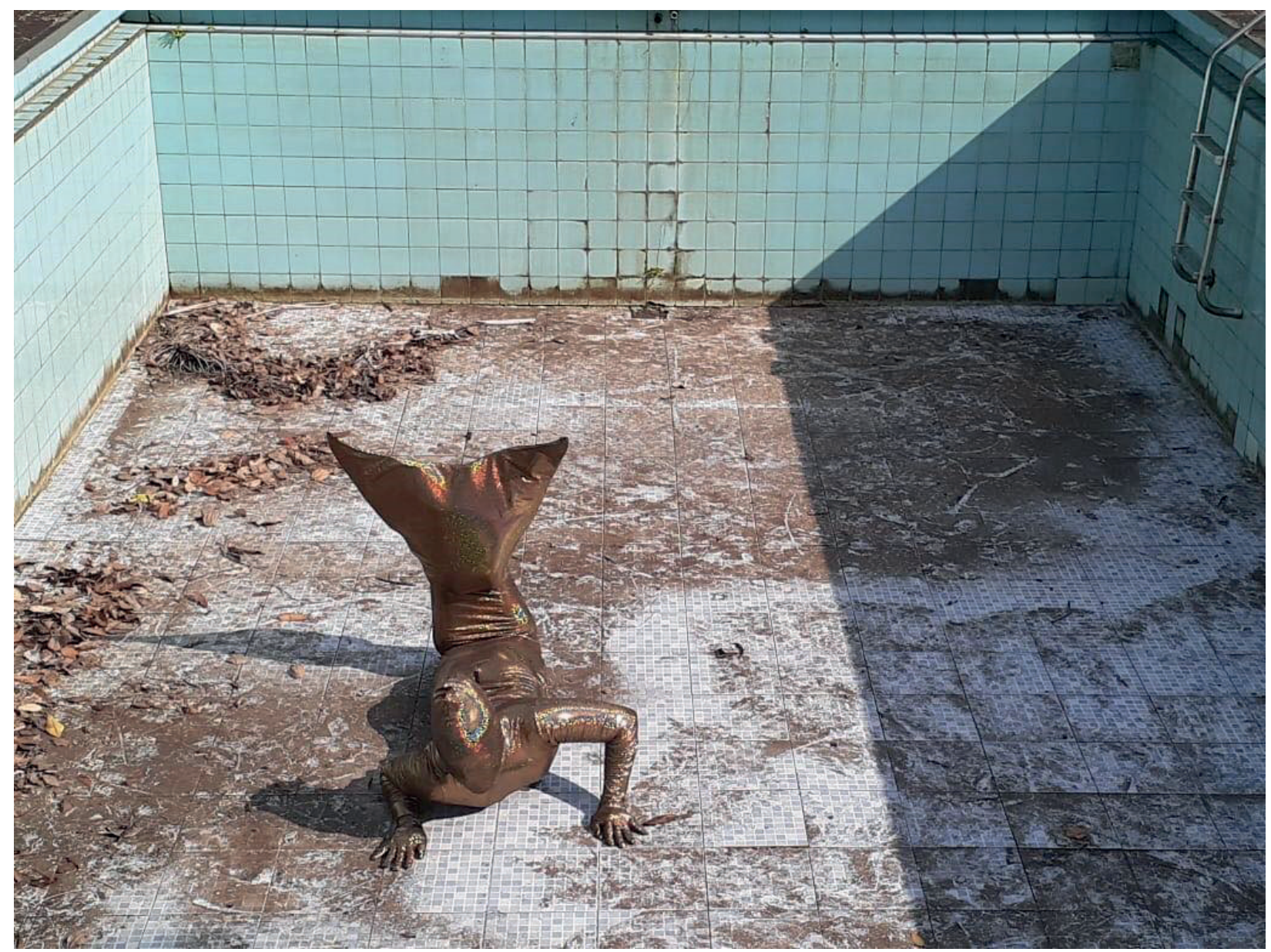

Figura 5 - Registro da performance orientada para o vídeo Sereia/zentai. Esta ação ocorreu em Mosqueiro, Pará, com participação de Rafael Bqueer como performer e produção de material fotográfico e em vídeo de Allyster Fagundes (PPGArtes/UFPA). Fonte: arquivo dx artista.

contra a pobreza, o racismo e a homofobia após sua ida para o Rio de Janeiro (BQUEER, 2020), também apresenta conexões com a infância de Bqueer.

Na minha infância em Ananindeua, no Pará, muitos se dirigiam a mim com apelidos homofóbicos. Faziam do bullying uma maneira de reprimir aquilo que não consideravam "padrão", reproduzindo a visão opressora de uma sociedade que não permite que crianças gays, negras e afeminadas possam exercer sua liberdade. Alguns termos com que me cobriam eu só pude compreender com o tempo; dentre eles, o apelido de Madame Satã. Na pré-adolescência, quando gradativamente fui perdendo o medo causado pela culpa de minha criação cristã, comecei a mergulhar sem auto-julgamentos nas referências LGBTQI+ que me fascinavam. Lembro que, aos 12 anos, vi uma revista com uma fotografia do filme Madame Satã (2002), protagonizado por Lázaro Ramos e dirigido por Karim Aïnouz. Como bom amante dos desfiles das escolas de samba que já era, me conectei com a imagem daquele corpo negro todo purpurinado, usando batom, gargalhando e extremamente sensual (BQUEER, 2020, p. 02).
Madame Satã, mais o conjunto visual apresentado em POC!!! Perfeita aos Olhos de Cristo firmaram outro marco pluritemporal e crítico em torno das memórias e das ausências de narrativas negras e queer na história oficial. A anacronia das imagens realocadas por Bqueer iluminaram tempos distintos de silenciamentos questionados, tempos distintos de resistências celebradas.

A contrapartida de reinserção destas imagens e narrativas nos circuitos institucionais das artes visuais de Belém pode igualmente ilustrar como os espaços das artes são também locais de poder e de disputa por narrativas. Sendo assim, a convocação de representações por Bqueer, retrabalhadas pela interferência irônica e digital de intertextualidade Warhol desde sua residência em Nova York, ilustraram e ilustram mais um capítulo em prol de uma sociedade que se deseja dialética, por tensionar diferenças, e antirracista, por partir de ações ativas. 


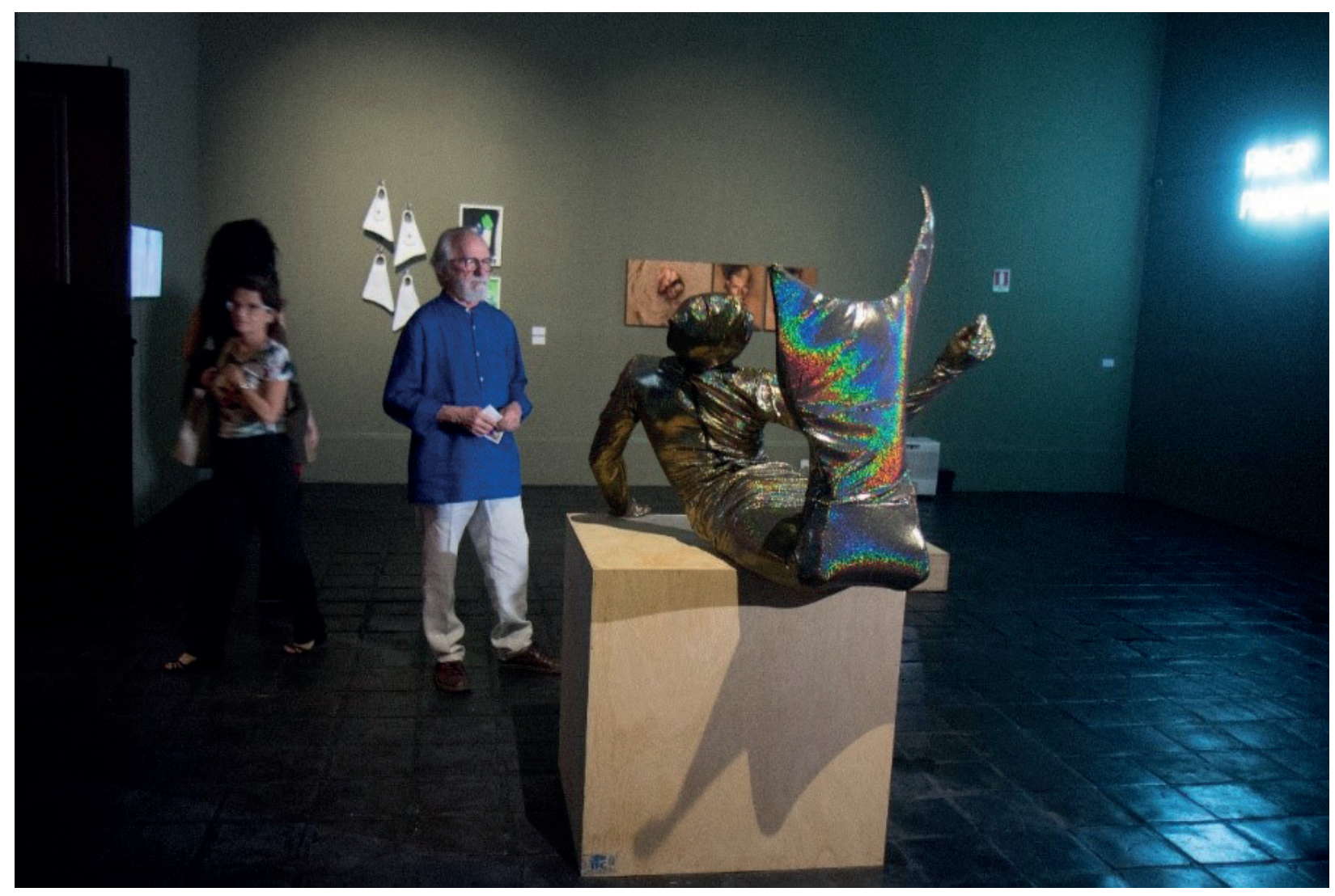

Figura 6 - Monique Lafond, uma das sereias, dialoga com Paes Loureiro na abertura do Arte Pará 2019, Malhas Afetivas, sob curadoria de Orlando Maneschy e curadoria adjunta de Keyla Sobral. Fotografia: Guido Elias.

\section{MONTAGEM BQUEER}

Em meu trabalho eu não peço permissão, eu invado as instituições. Sou corpo-guerrilha, sou um vírus que hackeia o sistema. Que debocha de títulos, reinvento palavras, mato a língua portuguesa, mato o colonizador. Em meu trabalho eu exponho que as imagens da cultura de massa nunca foram inofensivas. A fantasia que alegra o capitalismo é a mesma que esconde corpos negros dissidentes por de baixo de suas imagens de poder, seja na avenida paulista, na Disney ou na Time Square (Rafael Bqueer, Comunicação Pessoal).

A segunda experiência de Rafael Bqueer no segundo semestre de 2019 está ligada ao Arte Pará, Malhas Afetivas ${ }^{7}$, realizado no Museu Histórico do Estado do Pará (MHEP), com curadoria de Orlando Maneschy (ICA/ UFPA) e curadoria adjunta de Keyla Sobral (PPGArtes/ UFPA). Bqueer, neste caso, retomou sua própria poética sobre zentais ${ }^{8}$, de maneira a relacionálos com o signo das sereias, presentes em vários espaços públicos da capital, como é o caso da Praça Waldemar Henrique e da Praça da Sereia (Figura 05), sereias estas da cidade em uma configuração Art Noveau.
Para o dia da abertura deste Arte Pará, ocorrido na quinta-feira do 10 de outubro de 2019, Bqueer também agenciou quatro artistas Danilo Pontes, Sarita Themonia, Monique Lafond (Figura 06) e Demmora Damasceno -, as quais, vestidas igualmente de sereias em distintos cômodos do Museu, puderam se alinhar ao seu vídeo e reverberaram crítica artística sobre um sistema de narrativas e sobrevivências abraçadas pelo capitalismo tardo moderno ${ }^{9}$ para o silenciamento de performances desviantes ou para o silenciamento de corpos negros. O clímax da ação eclodiu a partir da revelação de quem se mostrava indefinível pelos trajes, em um possível diálogo com a premissa benjaminiana de que todo documento de cultura é também um documento de barbárie (ver BENJAMIN, 2011).

A percepção de montagem, delineada por Walter Benjamin e por Georges Didi-Huberman, pode ser articuladora eletiva para esclarecer este subtexto questionador. Já que a mesma pressupõe lugares assumidos estrategicamente por seus interlocutores - no caso de Bqueer e de sua rede 


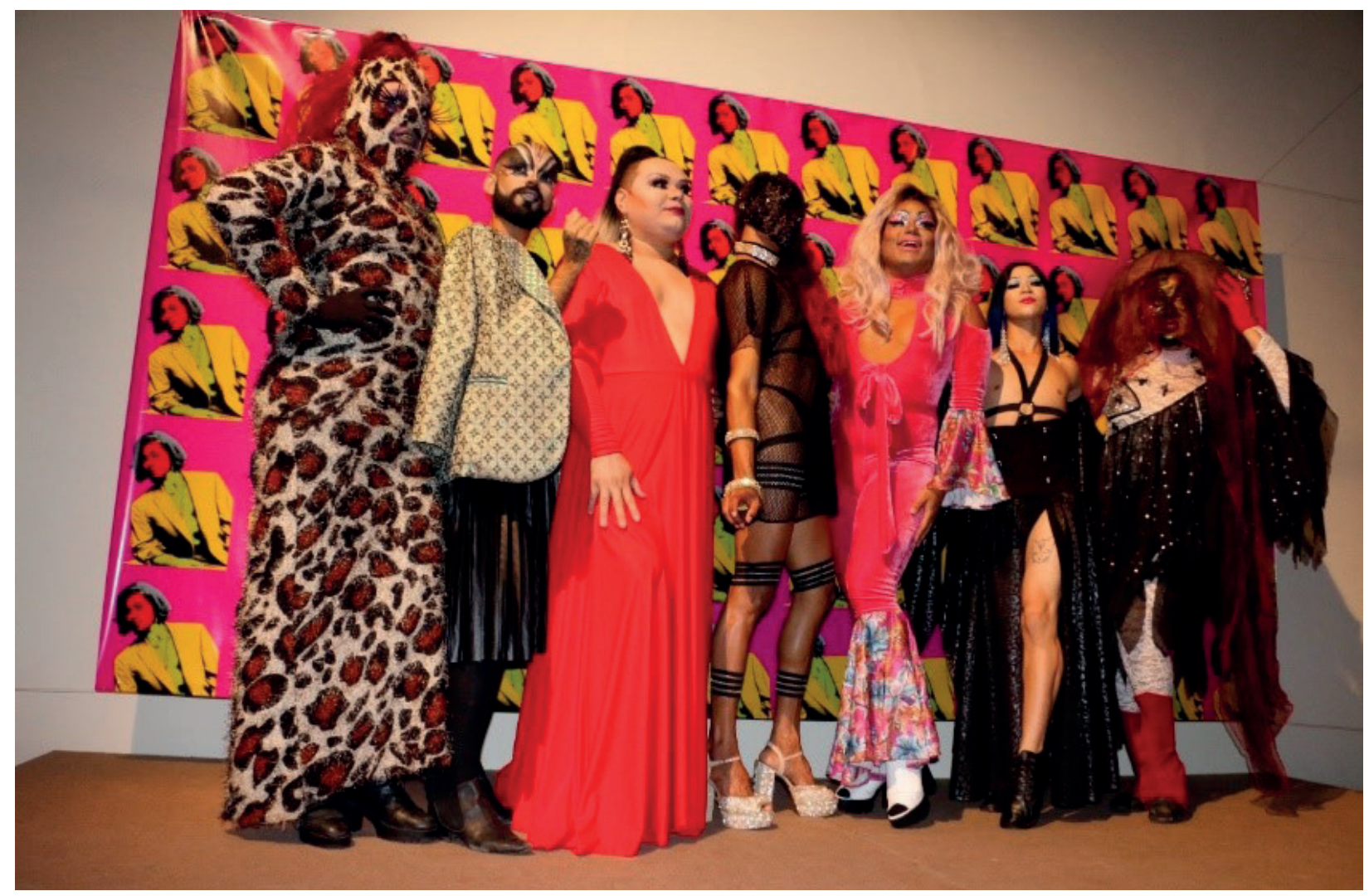

Figura 7 - Tristan Soledade, S1mone, Gigi Hibrida, Monique Lafond, Uhura Bqueer, Aurora Blondie, e Condessa Devonriver, da esquerda para direita, se apresentam no palco da instalação Tupiniqueer. Fotografia: Paula Sampaio.

de artistas, os lugares das identidades negras e LGBTQI+ no campo artístico -, pela montagem se desenha a construção de um saber histórico que, além dos fatos constatados, nesse caso a violência sofrida pelos grupos negros e LGBTQI+ no Brasil, pode carregar o que toca a pré e a pós-história ${ }^{10}$ destes mesmos fatos constatados, com vistas para seus lugares ressignificados e desejados (DIDI-HUBERMAN, 2017).

Por saber que "não há 'remontar' histórico senão pela 'remontagem' de elementos previamente dissociados de seu lugar habitual" (DIDI-HUBERMNAN, 2017, p. 121), Bqueer, filosófica e artisticamente, se engaja em uma visualidade polissêmica sobre as anacronias ${ }^{11} \mathrm{e}$ as contradições dos elementos que enredam os lugares e os tempos da história. Em sua operação artística de transgressão, reflete sobre novos espaços possíveis, espaços de representatividade e dignidade poética e política, com vias para a consciência e a convocação das memórias de corposnegroseLGBTQI+-relação constantemente tensa entre "memória e presente, entre presente e desejo, entre conhecimento descritivo e magia prospectiva" (DIDI-HUBERMAN, 2017, p. 228).

\section{ARTIVISMO BQUEER}

A terceira e última experiência deste circuito já se liga à instalação Tupiniqueer, homenagem às Manifestações Ambientais de Helio Oiticica, relidas como possibilidade de território simbólico de resistência e representatividade de grupos negros e LGBTQI+. Esta instalação foi apresentada no Sesc Ver-o-Peso, dia 04 de outubro de 2019, com minha curadoria e coordenação geral de Carol Abreu e Paula Sampaio. Tupiniqueer reuniu uma seleção das fotografias de Alex Korolkovas em torno da Pride 2019 e da ação performática de Bqueer na mesma, os vídeos Sex Ranger-Super Zentai e LeNoir, ambos apresentados no Instituto Tomie Ohtake por conta de sua premiação no EDP das Artes 2018, mais a participação das artistas e integrantes do coletivo Noite Suja ${ }^{12}$ (Figura 07 e 08), mediadas pela persona de Uhura Bqueer.

Como bem pontuado por Bqueer (Comunicação pessoal), a noite de 04 de outubro de 2019 


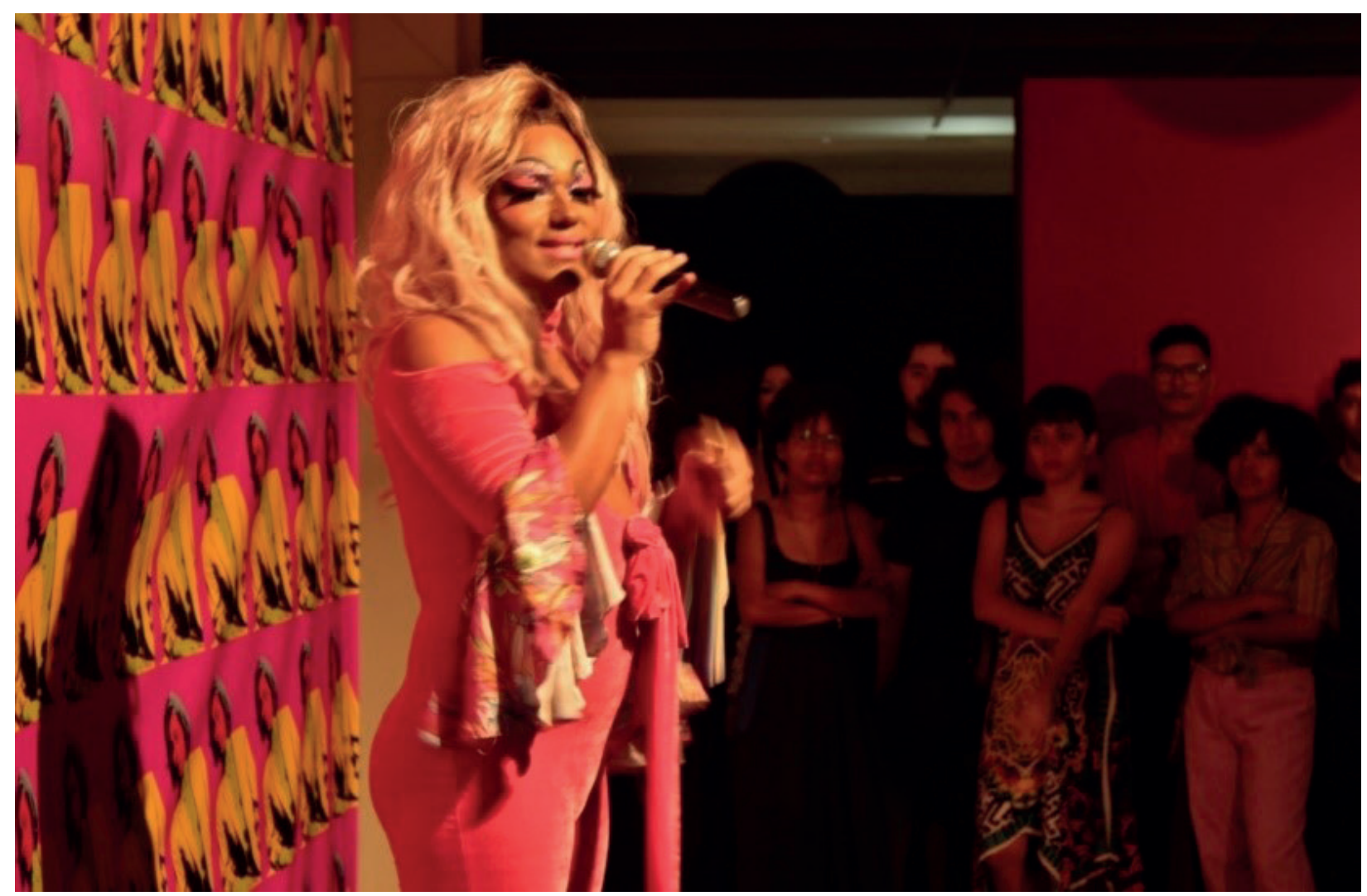

Figura 8 - Uhura Bqueer foi a persona que mediou a apresentação das artistas e Drag-themônias do Noite Suja na abertura da instalação Tupiniqueer.

Fonte: arquivo do autor.

apresentou um caráter de ampla significância para o circuito artístico belenense e nacional, não somente por conta da já prevista diminuição da programação artística do equipamento em face a uma política de sucateamento educacional e cultural nacional. Tupiniqueer, igualmente, agregou, através de uma equipe de produção e coordenação sensível e propositiva, um marco contra a LGBTfobia num momento chave para a história recente da Amazônia e do país.

O termo Artivismo, nesse sentido, se revela como uma possível opção conceitual para iluminar os bastidores constituintes desta instalação. Com sua factual união de artistas e produtores não somente de Belém, a mostra do Sesc Ver-o-Peso apresentou um caráter coletivo de realização e apoio, com destaque para as estratégias poéticas e performativas que subtendem vetores legíveis no terreno da arte política como alternativas de fruição e emancipação (RAPOSO, 2015), o nós político e histórico que parte do plano perceptual para o prático (DIDI-HUBERMAN, 2017).
À medida que a noite de apresentações de lip syncs ${ }^{13}$ transcorria, com mediação de Bqueer para a apresentação das artistas e drag queens, eram hasteadas bandeiras intangíveis da resistência de grupos postos no silenciamento, na exclusão e vítimas da violência. Uma vez que o caráter lírico e o caráter político se faziam entrelaçados para uma fruição artística e crítica em Tupiniqueer, tomo a compreensão de Georges Didi-Huberman (2017) sobre a escritura de afrontamento, em que a interrogação, para efeitos de duração, deve sobreviver à afirmação e à exclamação. Esta seria uma resposta, eletivamente análoga, para pensar em Tupiniqueer como faceta legítima e plural para se carregar o tempo de outras escrituras e resistências.

\section{ALGUMAS CONSIDERAÇÕES}

É preciso deseducar tudo que foi educado, reescrever todas as mentiras que nos foram narradas. Cabe a nós, pesquisadorxs, narradorxs dissidentes, pretxs, indígnxs, travestis, nãobinárias, que sempre existimos fora dessas 
instituições acadêmicas. Que agora exigimos responsabilização de uma culpa imposta sobre nós. Queremos reparação sobre os traumas impagáveis que fizeram com nossas tataravós escravizadas, com nossos avôs que não puderam ter nem o ensino fundamental completo. Exigimos reparo por nossas bisavós que foram domésticas, amas de leite, que tiveram que deixar a criação de seus próprios filhos para criar os filhos brancos que os brancos não cuidam. Queremos reparo e responsabilização pela morte de Miguel Otávio, que caiu do 9) andar de um prédio enquanto sua mãe Mirtis passeava com o cachorro de sua patroa, mulher branca, classe média alta de Recife. Nossos inimigos nunca usaram disfarce, tem cara, cor, imagem e semelhança dos mesmos corpos que chegaram em caravelas de além mar (Rafael Bqueer, Comunicação Pessoal).

Segundo dados do IBGE 2019, a população negra é a maior vítima de homicídios no Brasil, ao passo que, pelo relatório de 2020 do Grupo Gay da Bahia, nosso país é, ainda, o que possui o maior índice de violência contra as populações LGBTQ+ no mundo. Nesse sentido, um ponto significativo para destacar em torno das experiências artísticas de Rafael Bqueer na cidade de Belém em 2019, com as individuais POC!!! Perfeita aos Olhos de Cristo e Tupiniqueer, mais sua inserção no Arte Pará 2019 é o de que estas redes articuladas em equipamentos culturais locais e com parceiros e parceiras multilocalizadas não trazem perspectivas acríticas, mas de circuitos visuais amazônicos politicamente engajados para a sensibilização e a transformação social.

Desde sua primeira individual em Belém, intitulada As Aventuras de Alice no país do Baurets, realizada sob minha curadoria em 2015 no Atelier do Porto, de propriedade do artista Armando Sobral, que Rafael Bqueer projeta um papel político ativo para refletir sobre as condições assimétricas de existência na paisagem amazônica e em grupos negros e LGBTQI+ (ver mais em FLETCHER, 2018). Não por coincidência, sua produção tem se tornado um dos destaques em diversas exposições por assumir posição contra um projeto necropolítico em curso no Brasil, manejado por grupos hegemônicos que trazem a sobrevivência de um passado escravocrata e colonial para as fronteiras do presente.

Por seguir a premissa da filósofa Djamilla Ribeiro (2019), em interlocução com a poeta e ativista Maya Angelou, ou seja, a de que não basta não ser racista, mas antirracista, podemos tomar esta rede vasta de parcerias e equipamentos a partir da produção e agenciamento de Rafael Bqueer como historicidade construída, assumida entre lugares de fala e de escuta. A poética, bem dizem certas críticas, pode até ser considerada mero artifício sem resultados efetivos, todavia, assumimos defesa distinta, uma vez que compreendemos que quem esquece o passado ou mesmo o presente - e aqui imagens assumem posição pedagógica -, não poderá lhes escapar.

\section{NOTAS}

1. Agradecimentos ao Professor Dr. Ernani Chaves (PPGFIL/ UFPA) e a Rafael Bqueer pelas preciosas interlocuções.

2. A teoria do ponto de vista, ligada às expressões lugar de fala e lugar de escuta, apresenta uma observação crítica a um sistema patricarcal, heteronormativo e rascista que condiciona os discursos de grupos sociais, de maneira a lançar uma proposição de consciência combativa a este sistema (RIBEIRO, 2017; RIBEIRO, 2019).

3. A Necropolítica reflete criticamente sobre a prática de um regime de terror nos regimes coloniais tardo-modernos. Direciona seu debate para os manejos adotados por governos para decidir quem viverá, quem morrerá, e como viverão e morrerão certos corpos sociais, com ênfase para a vulnerabilidade de corpos negros (MBEMBE, 2011).

4. Relato realizado de forma remota pelo artista no dia 12 de agosto de 2020 .

5. POC, gíria inicialmente empregada como ofensa aos grupos das performances sociais negras e desviantes, é uma apropriação irônica, cínica e politizada. Também lida como Perfeita aos olhos de Cristo, esta tradução agrega corpos que não aceitam o encarceramento de regimes de exclusão e de violência.

6. Através da apropriação de imagens na Internet de figuras emblemáticas e negras, pertencentes ao universo LGBTQ+ brasileiro, Rafael Bqueer estabeleceu uma intertextualidade com 0 universo da Pop Art americana de Andy Warhol, com seus retratos reproduzidos em silk screen. Estes deslocamentos, já sob o título de UóHol, congregaram retratos de Jorge Lafond, Leona 
Vingativa e Madame Satã, neste recorte, mais Linn da Quebrada, Paulette, Márcia Pantera e Eloína dos Leopardos. A maioria destas imagens foram dispostas nas ruas de Nova York no formato de cartazes. Já em Belém, em produção em Fine Art, grande parte foi adquirida pelo Museu de Arte do Rio (MAR) a partir da exposição na Kamara Kó. Por sua vez, o MAR realizou uma mostra, com o mesmo título da série, UóHol, no primeiro semestre de 2020, sob curadoria de Marcelo Campos.

7. A premissa curatorial desta edição buscou homenagear o poeta e pesquisador João de Jesus Paes Loureiro, com uma interlocução propositiva para o debate deste em torno de sua poética do imaginário e de sua conceitualização sobre cultura amazônica (ver também PAES LOUREIRO, 2001).

8. A produção de Bqueer sobre zentais resultou no projeto Sex Ranger-Super Zentai, reflexão sobre erotismo, identidade e pós-pornô, a partir da apropriação de ícones da cultura de massa japonesa. Este projeto congregou fotografias e vídeos, de maneira a evidenciar relações entre o imaginário infantil hiper sexualizado dos anos 1990 e a influência dessas referências para se construir as relações entre os corpos e as identidades contemporâneas.

9. O capitalismo tardo moderno, conforme explicitado por Garcia Canclini (2008), implica em uma compreensão da porosidade das então fronteiras rígidas estabelecidas pelo racionalismo de Estados modernos. Nesse sentido, destacase o papel de diversos setores atuantes para uma heterogeneidade multitemporal de cada nação, com vias para cruzamentos socioculturais em que o tradicional e o moderno se misturam, gerando outras figuras complexas.

10. A pré e a pós história de fatos constatados traz como pano de fundo um debate de Walter Benjamin, como destaca Ernani Chaves (2003, p. 46), acerca de categorias ingênuas como a de desenvolvimento (Entwicklung). A posição de Benjamin contesta "concepções continuístas de histórias dominantes e, por consequência, com o próprio conceito de cultura e com a crença de que a história da cultura representava um 'avanço do conhecimento'".

11. A propósito da discussão sobre anacronia, Nicole Loraux (1992, p. 64) também desenha leitura sobre a eficácia de certos aspectos constituintes desta, desde que tomados com cautela, em um "sempre se deslocar para proceder às necessárias distinções". Em períodos de incertezas, fazer uso do que ultrapassa a narração ordenada, segundo a autora, pode garantir outra complexidade de compreensão do presente.

12. O coletivo Noite Suja vem fomentando um estilo-conceito de monstruosidade para a cena drag de Belém, estilo que se diferencia das demais cenas drag nacionais. Nesse sentido, termos como Drag-themônias ou drag(Themônias) são utilizados para destacar esta nuance conceitual do grupo.

13. Lip syncé um termo estrangeiro e popularmente conhecido para as dublagens de canções populares. Também influenciado pelo alcance do reality show americano RuPaul's Drag Race, este agrega apresentações de Drag Queens e Drag Kings que vão do espectro do dramático ao celebratório.

\section{REFERÊNCIAS}

BENJAMIN, Walter. Sobre o Conceito da História. In: BENJAMIN, Walter. Magia e Técnica, Arte e Política. São Paulo: Brasiliense, 2011, p. 222-232.

BQUEER, Rafael. Madame Satã: identidades negras LGBTQI+ e desfile das Escolas de Samba. Revista Caju, 2020. Disponível em < http://revistacaju. com.br/2020/06/17/madame-sata/>. Acesso em 30/07/2020.

CHAVES, Ernani. É possível uma história materialista da cultura? Walter Benjamin (re)lê Friedrich Engels. In: CHAVES, Ernani. No Limiar do Moderno: estudos sobre Friedrich Nietzsche e Walter Benjamin. Belém: Paka-Tatu, 2003, p. 35-50.

DIDI-HUBERMAN, Georges. Quando as Imagens tomam Posição: O Olho da História I. Belo Horizonte: UFMG, 2017.

DIDI-HUBERMAN, Georges. Diante do Tempo: História da Arte e Anacronismo das Imagens. Belo Horizonte: UFMG, 2019.

FLETCHER, John. Paisagens Impermanentes: Enredos Artísticos na Grande Belém. Jornal da

Associação Brasileira de Crítica de Arte (ABCA), v. 16, n. 47, 2018. 
FLETCHER, John. Rafael Bqueer: Arte e Ativismo nos 50 anos de Stonewall. In: O LIBERAL, Revista Troppo +, v. 74, 2019, p. $28-29$.

GARCIA CANCLINI, Nestor. Culturas Híbridas: Estratégias para entrar e sair da Modernidade. São Paulo: Edusp, 2008.

LORAUX, Nicole. Elogio do Anacronismo. In: NOVAES, Adauto (Org.). Tempo e História. São Paulo: Companhia das Letras: Secretaria Municipal de Cultura, 1992, p. 57-70.

MBEMBE, Achille. Necropolítica. São Paulo: N-1 Edições, 2011.

PAES LOUREIRO, João de Jesus. Cultura Amazônica: uma Poética do Imaginário. São Paulo: Escrituras, 2001.

RAPOSO, Paulo. Artivismo: articulando dissidências, criando insurgências. Cadernos de Arte e Antropologia, v. 04, n 02, 2015, p. 03-12.

RIBEIRO, Djamilla. 0 que é: lugar de fala. Belo Horizonte: Letramento, 2017.

RIBEIRO, Djamilla. Pequeno Manual Antirracista. São Paulo: Companhia das Letras, 2019.

\section{SOBRE O AUTOR}

John Fletcher é Professor Adjunto dos cursos de Bacharelado e Licenciatura em Artes Visuais, Faculdade de Artes Visuais (FAV/ UFPA), e do Programa de Pós-Graduação em Ciências do Patrimônio Cultural (PPGPatri/UFPA). É membro da Associação Brasileira de Crítica de Arte (ABCA). E-mail: coustonjf@gmail.com 